\title{
Wind pressure distribution influence on natural ventilation for different incidences and environment densities
}

\author{
Geoffrey van Moeseke*, Elisabeth Gratia, Sigrid Reiter, André De Herde \\ Architecture et Climat, Faculté de Sciences Appliquées, Université Catholique de Louvain, 1 place du Levant, 1348 Louvain-la-Neuve, Belgique
}

Received 20 September 2004; received in revised form 12 November 2004; accepted 23 November 2004

\begin{abstract}
Natural ventilation is of increasing interest in building industry because of recent focus on environmental concern, considered with both comfort and economical criteria. The aim of this study is to investigate how wind may induce natural ventilation, with focus on wind incidence and large scale environment density influences. These parameters modify flows inside and outside buildings. Numerical dynamic simulations are achieved for a standard office building using pressure coefficients obtained from a parametrical model. Simulations allow to describe inside building air flow for three incidences: $0^{\circ}, 45^{\circ}, 90^{\circ}$ and three theoretical environments: open, suburban and urban. Originality of this study is to work with both vertical and horizontal pressure coefficient gradients. Results show how important horizontal gradients are in air flow comprehension. Urban wind driven ventilation potential is also discussed. Some words are said on existing tools limitations. The need for further studies is illustrated in order to obtain handy pressure coefficients prediction tools and to optimize openings mechanical regulation. The all study falls under the step of sustainable architecture.
\end{abstract}

(C) 2004 Elsevier B.V. All rights reserved.

Keywords: Natural ventilation; Indoor air flow; Pressure coefficient; Wind; Office building

\section{Introduction}

\subsection{Natural ventilation in building and energy}

One of the fundamental aspects of architecture is to provide comfort to the inhabitant. This is done by wall insulating, heating, protecting from the sun and managing fresh air intake. In this context, natural ventilation is an important tool when used along with sufficient thermal inertia. It enhances air quality by dissolution of pollutants and thermal comfort by refreshing building's mass, especially when night cooling is created.

But interest in ventilation is double since energy concern takes more and more place. This concern has emerged last decades, brought by energy efficiency objectives and cost saving opportunities. On one hand, ventilation may be a powerful cheap temperature control tool in buildings if well conceived. On the other hand, it can be an important potential of energy losses if not. In winter

* Corresponding author. Tel.: +32 104721 38; fax: +32 10472150 .

E-mail address: vanmoeseke@arch.ucl.ac.be (G. van Moeseke). time, fresh air intake represents around 30\% of office buildings heating energy needs. And in summer time, extensive night cooling in buildings with strong inertia can be developed to avoid day overheating and expensive and energy consuming refrigerating systems. These examples illustrate the place of mechanical or natural ventilation in energy concern.

Ventilation based on natural forces (buoyancy forces or wind pressure) should always be preferred to mechanical ventilation. In European climates, natural forces can efficiently complete comfort and energy objectives without fans' energy consumption. But, therefore, it must be well conceived and regulated. Mechanical ventilation should be limited to particular situations when sufficient natural air flow cannot be achieved.

\subsection{Wind and natural ventilation}

Wind influence on natural ventilation is obvious. By creating high and low pressures on buildings' different faces, wind creates air flows inside buildings. These 
movements are strongly dependents on wind pressure gradients. Wind flow and wind pressure distributions on buildings are then important fields of investigation explored by lots of authors.

Some of them try to determine pressure profiles on buildings for different incidences [1], neighbour buildings configurations [2] or local environment densities [3]. Others try to describe buildings or topography influence on wind flow [4,5]. Finally, some authors investigate particular configurations as street canyon [6]. But all these studies are made aside where a systematic approach appears necessary to obtain effective comprehension of pressure distributions on buildings [7].

Only a few authors study connection between environmental interferences created in wind flow and natural ventilation potential, partly because softwares combining thermal study and air movements are quite recent, partly because it is a younger concern and partly because it is dependent of more accurate knowledge in fluid dynamics. In particular, description of air flow downstream obstacles needs further developments. Some studies although exist, made with wind tunnel experiments [8] or numerical tools. Among these last the study of Gratia et al. [9] is of greatest interest because it discusses natural ventilation in office buildings for different environments and wind influences. Major limitation of this study is to use only vertical pressure distributions. Results are then theoretically correct for a building of infinite length.

\subsection{Aim of this study}

This study follows Gratia et al.'s. It goes one step forward by taking into account as well horizontal as vertical pressure coefficients gradients. Objective of this study is to bound complete description of pressure coefficients repartitions on building for different wind incidences and built environments with architectural concern about natural ventilation. Indeed architecture may be defined as the creation of a building in a particular context. High quality architecture for example is able to combine constraints of local and global context with particular programmatic, structural and aesthetic specificities. It is then necessary to pursue studies on environment influence on buildings to promote buildings of quality. Such study is then part of a sustainable architecture definition.

Practically, use of horizontal and vertical pressure distributions allows our results to be applied to real buildings. These results are then useful complements for architects and HVAC designers in buildings and systems design.

By numerical simulations this study will investigate inside flow and flow rates modifications for $0^{\circ}, 45^{\circ}$ or $90^{\circ}$ wind incidence and open, suburban or urban environment. Urban natural ventilation potential will be discussed, as well as city densities limits. Importance of accurate knowledge of vertical and horizontal pressure gradients will be illustrated.

\section{Theory}

Before describing our study methods and obtained results, some theoretical notions can be useful.

Wind in lowest parts of atmosphere undergoes friction and viscosity effects. Wind behaviour can be described by the boundary layer model. Such a layer develops itself between the ground surface and firsts hundreds meters altitude. Wind profile in this boundary layer can be accurately enough described by an exponent profile:

$V_{z}=V_{g}\left(\frac{z}{h}\right)^{1 / \alpha}$

where $V_{z}$ is wind speed at height $z ; V_{g}$, wind speed outside the boundary layer; $h$, the layer height; and $\alpha$, a coefficient describing ground density. Index $g$ is chosen to represent the free stream wind. This wind can be represented by the "gradient wind" model [10].

Greater ground density will increase boundary layer height and decrease $\alpha$ value. Following values are proposed by Melaragno [11]: boundary layer height can be set to $275 \mathrm{~m}$ in open environment, $365 \mathrm{~m}$ in suburban environment and $460 \mathrm{~m}$ in urban environment while adequate values for $\alpha$ are, respectively, 7, 4.5 and 3 in the same environments. Exponent $1 / \alpha$ then takes, respectively, the $0.14,0.22$ and 0.33 values.

Using such determined values is of course simplified. But more accurate developments of the relation between ground configuration and wind profile description are useless here. Indeed this study worked with three theoretical ground configurations and did not investigate continuous density variations.

Simple algebraic developments allow to determine suburban or urban speed from meteorological data usually given for open environments. Following development is based upon hypothesis of constant gradient wind speed above boundary layer. Considering 1 and 2 indexes as two different environments, this hypothesis is written:

$$
\begin{aligned}
& v_{g_{1}}=v_{g_{2}} \\
& \frac{v_{z_{1}}}{\left(z_{1} / h_{1}\right)^{1 / \alpha_{1}}}=\frac{v_{z_{2}}}{\left(z_{2} / h_{2}\right)^{1 / \alpha_{2}}} \\
& v_{z_{2}}=v_{z_{1}}\left(\frac{h_{1}}{z_{1}}\right)^{1 / \alpha_{1}}\left(\frac{z_{2}}{h_{2}}\right)^{1 / \alpha_{2}}
\end{aligned}
$$

Using $h$ and $\alpha$ values given above, passing from one environment and altitude to others is easy.

Next notion exposed here is the pressure coefficient $\mathrm{Cp}$ :

$$
\begin{aligned}
& \mathrm{Cp}=\frac{p-p_{\text {ref }}}{p_{\text {ref }}} \\
& p_{\text {ref }}=\frac{1}{2} \rho v_{\text {ref }}^{2}
\end{aligned}
$$

Where $p$ is the measured pressure on buildings sides and $p_{\text {ref }}$ is a chosen dynamic reference pressure. Such definition allows to compare results of various studies as long as the same reference is chosen. Usually reference speed is 


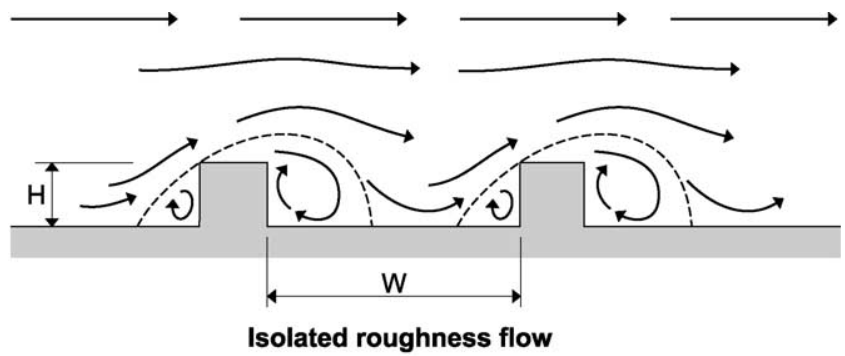

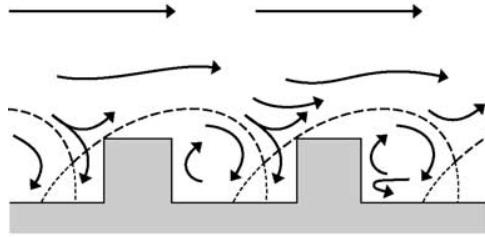

Wake interference flow

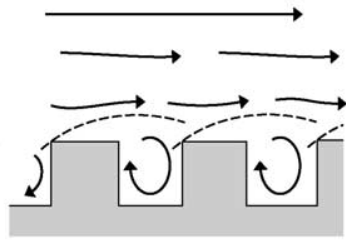

Skimming flow
Fig. 1. Three types of flow following relative distance between buildings.

taken as the wind speed at roof height without the building's presence. Gradient speed is sometimes chosen by authors.

Finally, it is useful to remind three types of flows may occur in built environment when considering street canyons with orthogonal wind [4]. In function of relative distance between buildings, wake can fully or partially develop. It causes what can be called "isolated roughness flow" and "wake interference flow". If buildings are still closer, stable vortexes appear in the canyon and a "skimming" flow regime occurs where the bulk of the flow does not enter the canyon (Fig. 1).

Passage between isolated roughness flow and wake interference flow occurs when street wide equals around three building heights. Passage between wake interference and skimming flow occurs when street wide equals around 1.5 building heights [4].

\section{Method}

Now that objectives of this study are exposed and basic notions are reminded, experimentation methodology can be described. First point is the way pressure coefficients are obtained. Then the simulation program is described, along with the studied building. Finally meteorological assumptions are exposed.

\subsection{Pressure coefficient input values}

Numerical tools allow to study inside air flows more accurately than wind tunnel test because radiative solar gains, internal gains or openings variations for example may be taken into account. Numerical simulations' quality is based on high confidence input data. The difficulty is then to found adequate $\mathrm{Cp}$ values for the studied buildings and environments. Such values may be obtained in four different ways: by real scale measurements, by wind tunnel investigations, by computational fluid dynamics studies or by the use of simplified parametrical models.

\subsubsection{Real scale measurements}

Real scale measurements are of course the most precise way. It gives a precise idea of pressures on a particular building in a specific environment. But limitation to specific building's shape and especially to unique environment give less relevant results. Furthermore, such real scale measurements are made inappropriate by time and cost limitations.

\subsubsection{Wind tunnel tests}

Wind tunnel test may give more relevant results because changes in building shapes or pattern are made easily. Working with models makes you able as well to study some precise location as to test different hypothesis. Limitation of wind tunnels is the scarcity of such tools, especially of big tunnels needed for investigations on urban models. Nevertheless, wind tunnels are the principal source of pressure coefficients values and stay a reference for new methods' validity investigations.

\subsubsection{Computational fluid dynamics}

Computational fluid dynamics simulations have the same advantages as wind tunnel tests. Only computer power would theoretically limits possible investigations. Unfortunately, accuracy of such tools must still be enhanced. Especially when working on complex turbulent air flows as we do in the field of wind influence on buildings' behaviour. Therefore, architectural applications of CFD's developments are still at the beginning.

\subsubsection{Parametrical models}

Finally, simplified models exist, based on wind tunnel experiments, which are handy and time and cost saving. These models propose correlations between some parameters to evaluate approached pressure coefficients. Of course, confidence in results is weaker than for wind tunnel tests. But this kind of models is a solution to promote natural ventilation concern among architects who can't afford expensive or technical scientific work. Such a model, proposed by Grosso [12], has been used for this study.

\subsubsection{Grosso parametrical pressure model description}

M. Grosso's model is based on wind tunnel experiments and takes three kinds of parameters into account (Fig. 2):
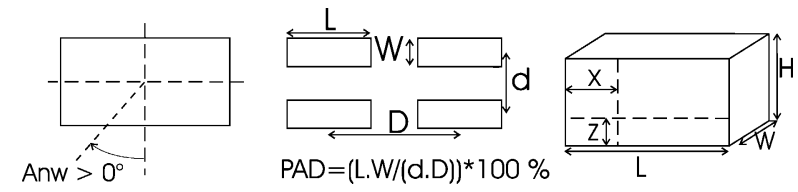

Fig. 2. Wind incidence (left), definition of plan area density "pad" (centre) and building's main dimension's symbols (right) in M. Grosso's model. 
- Climatic parameters: wind profile exponent and wind incidence;

- Environmental parameters: plan area density "PAD" and relative building height "rbh";

- Geometrical parameters: building proportions represented by frontal aspect ratio "far" $=L / H$ and side aspect ratio "sar" $=W / H$.

Results of this model are pressure coefficients as defined above (Eq. (5)) with reference pressure take as the wind dynamic pressure at roof height evaluated without the studied building. This definition matches with the needed inputs of the chosen inside air flow simulation program. Pressure coefficients values are calculated for 81 taps on a building's side regularly disposed on a grid's nodes. Nodes' relative positions on building's side are $0.07,0.2,0.3,0.4$, $0.5,0.6,0.7,0.8$ and 0.93 in both vertical and horizontal directions.

Validity of this model was verified by comparing obtained pressure coefficients repartition with other published pressure coefficients profiles.

Fig. 3 shows pressure coefficients repartitions measured in wind tunnel by Cermak [13] and those predicted by M. Grosso's model. Both are given for an isolated cube in an open environment.

On windward side, it may be seen that M. Grosso's model estimates quite well pressure coefficients. Maximum pressure is obtained by M. Grosso's model at two-third of the cube height while Cermak's measures place it on the top of the side. Other comparisons were made with Wiren [2] and Richards et al. [1] studies for examples which comfort M. Grosso's predictions. On lateral side M. Grosso's model also fits accurately with Cermak's measures. On leeward side results are really different. M. Grosso's vertical gradient differs from Cermak's regular low negative pressures pattern. Other studies also shows regular patterns but discuss numerical precise value (between -0.1 and -0.4 ) $[1,2]$. Measure and prediction of leeward pressure coefficients values are a difficult matter because flow is strongly turbulent and non-stationary. For this study, confidence will be brought to Grosso's model in order to obtain whole coherent results. Reader should keep the hypothesis in mind when comparing results of this study with other publications. Except this point, results are judged consistent with literature.

\subsubsection{Grosso parametrical pressure model calibration}

This model has to be calibrated to describe three different environments labelled "open, suburban and urban". Therefore, mean pressure coefficients values are drawn from IEA publications [14]. Such mean values are given for three situations named "exposed, partly shielded, shielded". Correspondence is assumed between these two panels of environments. Labels "suburban" and "urban" must then be comprehended as descriptive of an ideal situation and not as real situations which would have been modelled.

The objective is here to find adequate values for $\mathrm{M}$. Grosso's model's parameters in order to obtain pressure coefficients repartitions which means values fits IEA's proposed values. Most of the adequate values for $\mathrm{M}$. Grosso's model parameters are obtained three different ways:

- Wind profile exponents are described in literature and adequate values for such kind of environments can be found. This study follows M.G. Melaragno and takes 0.14, $0.22,0.33$ as exponent values for, respectively, open, suburban and urban environments [11];
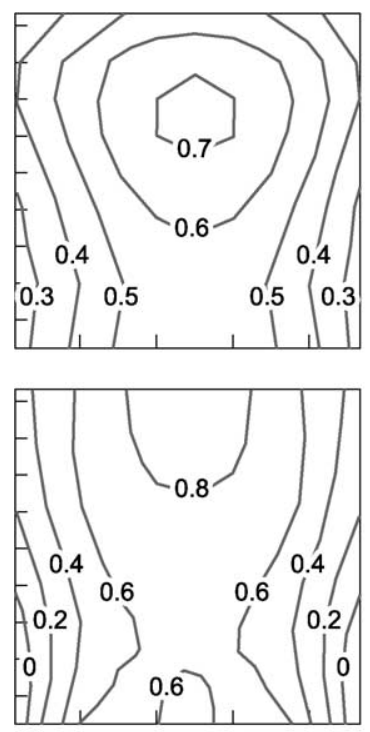

Side 1
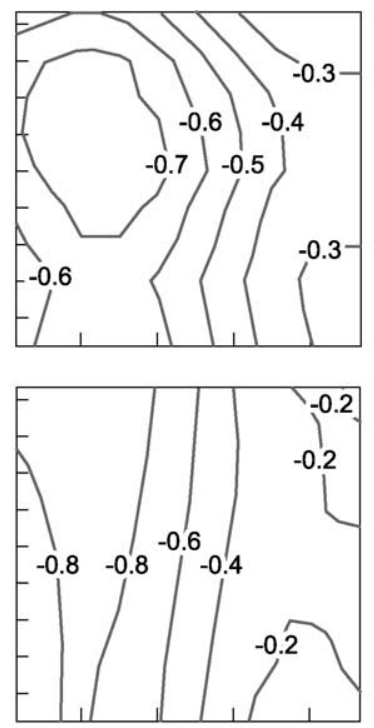

Side 2
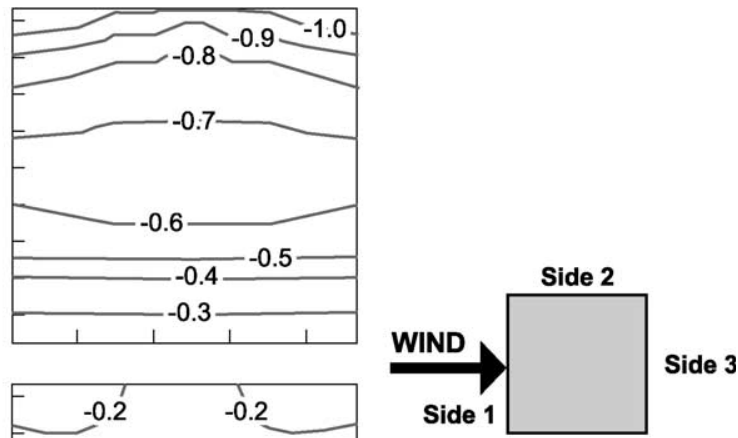

Side 3

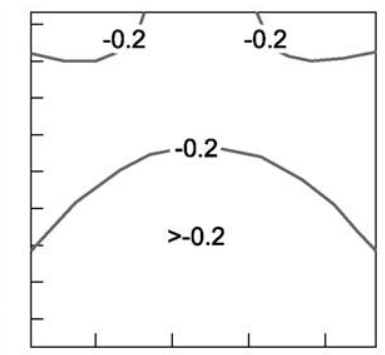

Side 3

Fig. 3. Comparison of pressure coefficients modelled by M. Grosso's model (above) and measured by Cermak (below) for a cube in an isolated environment. 
Table 1

Summary of the parameter's values introduced in M. Grosso's model in order to represent open, suburban and urban environments

\begin{tabular}{llll}
\hline & Open & Suburban & Urban \\
\hline Wind profile exponent & $0.14^{\mathrm{a}}$ & $0.22^{\mathrm{a}}$ & $0.33^{\mathrm{a}}$ \\
Far & $1^{\mathrm{b}}$ & $1^{\mathrm{b}}$ & $1^{\mathrm{b}}$ \\
Sar & $1^{\mathrm{b}}$ & $1^{\mathrm{b}}$ & $1^{\mathrm{b}}$ \\
Rbh & $1^{\mathrm{d}}$ & $2^{\mathrm{b}}$ & $1^{\mathrm{b}}$ \\
Pad & $0^{\mathrm{c}}$ & $12.5^{\mathrm{d}}$ & $7.5^{\mathrm{d}}$ \\
\hline
\end{tabular}

${ }^{\mathrm{a}}$ Deduced from literature.

${ }^{\mathrm{b}}$ Given by IEA.

c Assumed.

${ }^{\mathrm{d}}$ Fitted.

- Some parameters values are given by IEA when describing validity of proposed mean values: proportions, relative building height (rbh) if shielded or partly shielded, and incidence;

- Finally, plan area density value in open environment is logically set to 0 .

Still missing values are relative building height for open environment and plan area density for suburban and urban environments. These are found using fitting procedures: $\mathrm{M}$. Grosso's model is used for different values of the missing parameters and those giving the closest results from IEA's mean pressure coefficients are retained. With this procedure it is found that adequate values are $\mathrm{rbh}=1$ for open environment and pad $=12.5$ and 7.5, respectively, for suburban and urban contexts. Table 1 summarises all parameters $\mathrm{v}$ alues for the three environments.

Now that this model is calibrated, pressure coefficients may be obtained to evaluate natural ventilation potential. A computational tool is, therefore, needed.

\subsection{The TAS program}

TAS is a software package for the thermal analysis of buildings [15]. It includes a 3D modeller, a thermal/energy analysis module, a systems/controls simulator and a 2D CFD package. This software is then a complete solution for the thermal simulation of buildings. It is also a powerful design tool for optimization of buildings environmental, energy and comfort performances.

TAS provides default pressure coefficients evaluation based on wind tunnel tests for a high rise building. These coefficients values are given only following relative height and so are not horizontal relative position dependant. So, it is not adequate to represent air flow for a whole building. But TAS allows users to manually introduce pressure coefficients values for every opening. This is what has been done for this study, using M. Grosso's parametrical model to obtain needed inputs.

\subsection{The studied building}

The simulations were realized on the building proposed in the frame of the subtask A of the task 27 (performance of solar façade components) in the International Energy Agency-Solar Heating and Cooling Program. Nevertheless, some modifications were brought to the building to adapt it to Belgian practices and make results comparable with those of Gratia et al. The building is a middle-size office building. One hundred and fifty office modules are aligned over five floors and two facades, separated by a central corridor. Facades orientations are set north and south. Service spaces find place at both ends of the building. This kind of narrow plan is adequate to natural ventilation due to wind. Specific spaces such as atrium or deep buildings with few natural ventilation potential are not studied here. Such spaces bring particular questions while wind effect on classical buildings is here the major point of interest.

Each office has four openable windows (two top and two below) on the external wall and one more on the internal wall between office module and corridor (Fig. 4). It allows cross ventilation.

Two different zone divisions are made. The first one divides each storey in nine zones. The second one, used to

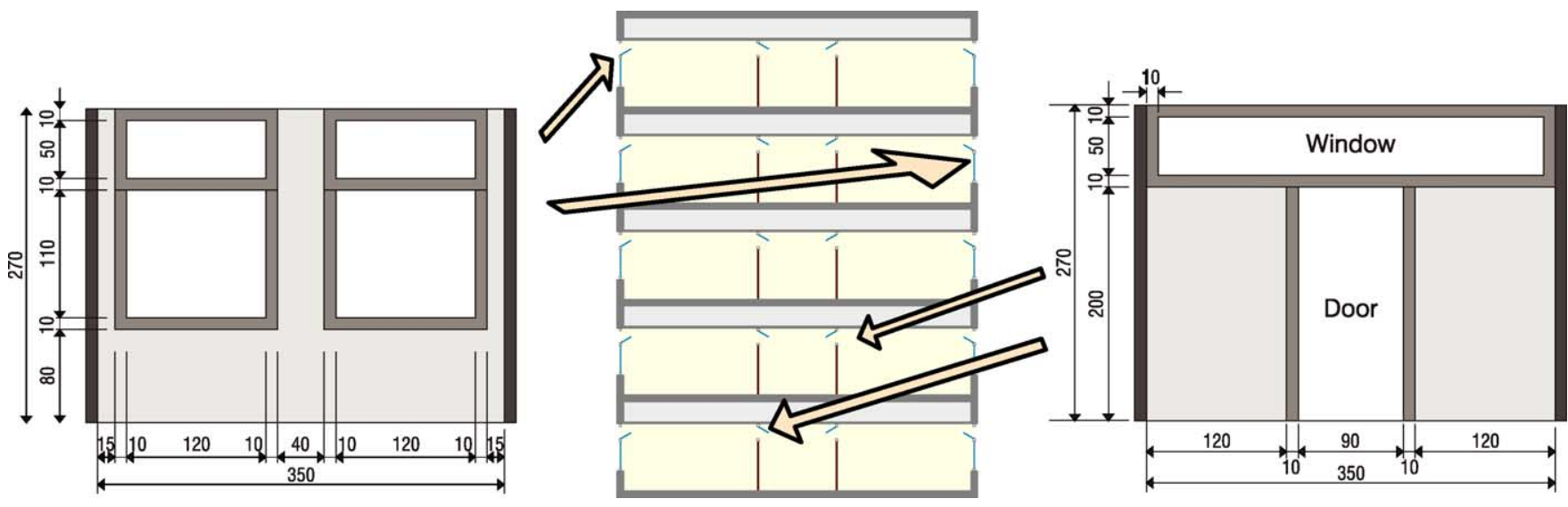

Fig. 4. Modelled building section. 


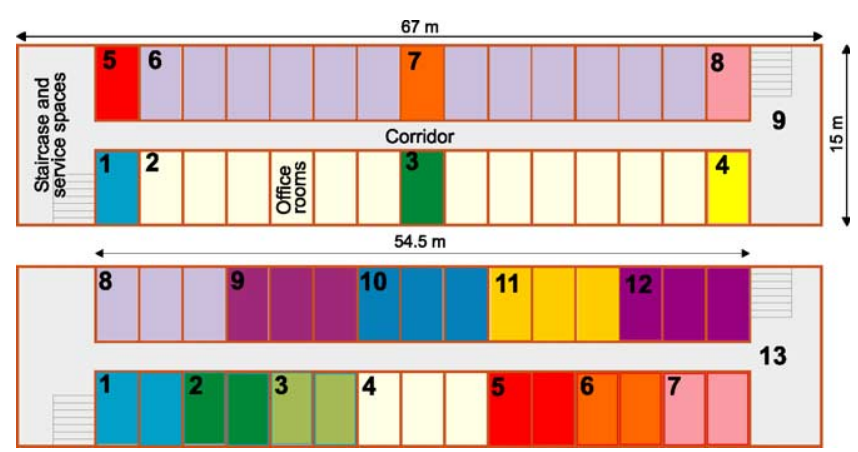

Fig. 5. Two used zones subdivisions of a storey.

study more accurately one storey, divides the fourth storey alone in 13 zones (Fig. 5).

Pressure coefficients corresponding values for each zone was determined following M. Grosso's model's grid nodes locations and zone position in the building. Considering vertical position, pressure coefficients corresponding to 0.07 relative height are used for the first storey. Those of 0.3 relative height are set to the second floor, and so on with the $0.5,0.7,0.93$ relative heights and third, fourth and fifth storeys. Considering horizontal position, linear relations are considered between the nearest nodes for each zone. Those relations are summarized in Table 2.

Some other building's characteristics are described here: thermal properties, use of building and internal gains.

\subsubsection{Thermal characteristics}

Thermal performance of the envelope is described by thermal conductibility $U$ of components:

- Roof, $U=0.3 \mathrm{~W} \mathrm{~m}^{-2} \mathrm{~K}^{-1}$,

- Ground floor: $U=0.38 \mathrm{~W} \mathrm{~m}^{-2} \mathrm{~K}^{-1}$,

- Intermediate floor: $U=0.86 \mathrm{~W} \mathrm{~m}^{-2} \mathrm{~K}^{-1}$,

Table 2

Linear relations between pressure coefficients following horizontal relative position of zones in the two used patterns

\begin{tabular}{|c|c|}
\hline Zone no. & $\mathrm{Cp}$ relations \\
\hline \multicolumn{2}{|c|}{ First zone pattern } \\
\hline 1 and 5 & $0.5^{*} \mathrm{'Cp} 7 \%$ ' $+0.5^{*}$ 'Cp20\%' \\
\hline 2 and 6 & 'Cp30\%' \\
\hline 3 and 7 & 'Cp50\%' \\
\hline 4 and 8 & $0.5^{*}$ 'Cp80\%' + 0.5 ' $\mathrm{Cp} 93 \%$ ' \\
\hline \multicolumn{2}{|c|}{ Second zone pattern } \\
\hline 1 & $0.25^{*} ' \mathrm{Cp} 7 \%$ ' $+0.75^{*}$ 'Cp20\%' \\
\hline 2 & $0.25^{*}$ 'Cp $20 \%$ ' $+0.75^{*}$ ' $\mathrm{Cp} 30 \%$ ' \\
\hline 3 & $0.2^{*} \mathrm{Cp} 30 \%$ ' $+0.8^{*} \mathrm{Cp} 40 \%$ ' \\
\hline 4 and 10 & 'Сp50\%' \\
\hline 5 & $0.2^{*}$ 'Cp60\%' + 0.8*' 'Cp70\%' \\
\hline 6 & $0.25^{*}$ 'Cp $70 \%$ ' + 0.75*' 'Cp80\%' \\
\hline 7 & $0.25^{*}$ 'Cp $80 \%$ ' + 0.75*'Cp93\%' \\
\hline 8 & 'Сp20\%' \\
\hline 9 & $0.5^{*}$ 'Cp30\%' $+0.5^{*}$ 'Cp $40 \%$ ' \\
\hline 11 & $0.5^{*}$ 'Cp60\%' + 0.5 'Cp70\%' \\
\hline 12 & 'Cp80\%' \\
\hline
\end{tabular}

- Opaque part of facade: $U=0.37 \mathrm{~W} \mathrm{~m}^{-2} \mathrm{~K}^{-1}$,

- Internal walls: $U=0.42 \mathrm{~W} \mathrm{~m}^{-2} \mathrm{~K}^{-1}$,

- Low-emissivity double glazing: $U=1.8 \mathrm{~W} \mathrm{~m}^{-2} \mathrm{~K}^{-1}$ with solar factor for direct transmission: 0.62 .

Other constructions properties are:

- Absorptance for solar radiation exchange is 0.5 for both internal and external opaque surfaces;

- Emissivity for thermal radiation exchange is 0.9 for both internal and external opaque surfaces;

- The assumption is made of no air infiltration;

- Ventilation rate is consistent with Belgian regulations (1 ach). The hygienic air comes inside the building at outside temperature. Income of air is natural (external air).

\subsubsection{Use of the building}

Occupation was assumed identical every day of the week, so that occupation variations could not influence results. Use of building is then $10 \mathrm{~h}$ a day (08:00-18:00 h), 7 days a week.

\subsubsection{Internal gains in offices}

Three kinds of internal gains have to be considered in office modules. First are internal gains due to occupants and then due to equipment and lighting. Internal gains in office modules are resumed in Table 3.

Internal gains in corridor and service spaces are only due to lighting. Lighting power installed, including the power of ballast/starter is $0.92 \mathrm{~W} \mathrm{~m}^{-2}$ in corridor and $5 \mathrm{~W} \mathrm{~m}^{-2}$ in service spaces, with constant $100 \%$ switched-on percentage.

HVAC system regulation is made as follows: setting temperature for heating is $21^{\circ} \mathrm{C}$ from Monday to Friday, between 7 a.m. and 6 p.m., setting temperature is $15^{\circ} \mathrm{C}$ the rest of the time. Setting temperature for cooling is $24{ }^{\circ} \mathrm{C}$ from Monday to Friday, between 7 a.m. and 6 p.m., there is no setting temperature the rest of the time

At last, some climatic assumptions were made.

\subsection{Climatic data assumptions}

Simulations were performed with climatic data of Uccle, Belgium. The weather data were recorded by the Belgian Royal Institute of Meteorology and consist of 12 actual months, representative of the average climate at Uccle. For this study, a sunny summer day (July 24) was chosen. This

Table 3

Internal gain in office modules

\begin{tabular}{lll}
\hline Occupants & Equipment & Lighting \\
\hline Two person/office module & Two PC/office module & \\
$80 \mathrm{~W} /$ person & $160 \mathrm{~W} / \mathrm{PC}$ & $13 \mathrm{~W} \mathrm{~m}^{-2}$ \\
$84 \%$ presence & $67 \%$ switched-on & $84 \% \mathrm{switched}^{-o n}$ \\
$7.11 \mathrm{~W} \mathrm{~m}^{-2}$ & $11.4 \mathrm{~W} \mathrm{~m}^{-2}$ & $10.92 \mathrm{~W} \mathrm{~m}^{-2}$ \\
\hline
\end{tabular}




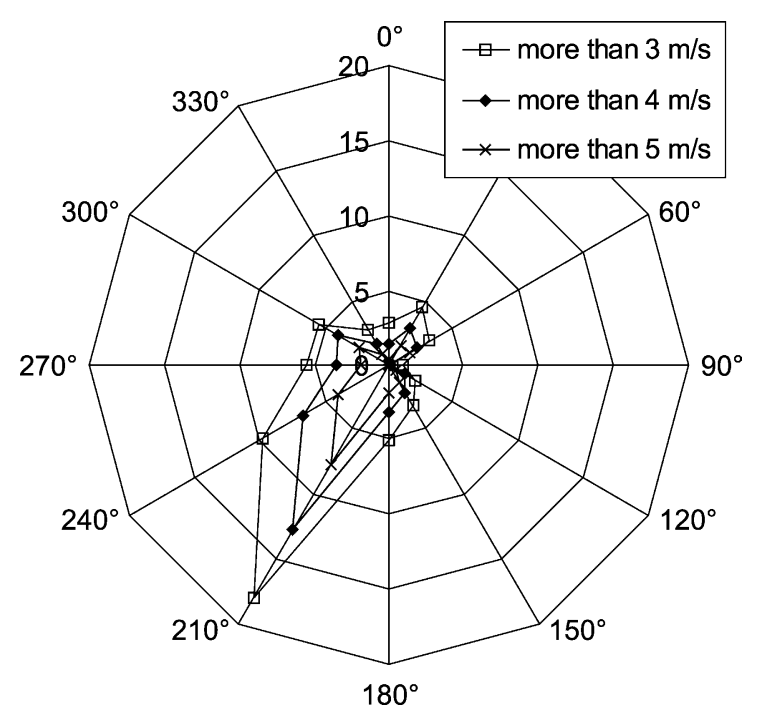

Fig. 6. Annual frequency of wind (in percentage) for $30^{\circ}$ sectors and different minimal wind speed.

choice considers that impact of natural ventilation on comfort and cooling economy is greater by hot days.

The outside temperature evolves between $11.4{ }^{\circ} \mathrm{C}$ and $23.3{ }^{\circ} \mathrm{C}$. The global solar radiation is important. For wind, used data are not mean July 24 Uccle data but global Belgian mean wind data. Monthly Belgian mean wind speeds at $10 \mathrm{~m}$ and directions show regularity in both parameters. Fig. 6 shows that this regularity remains when considering only some wind speed levels. Of course, wind variations exist in short time period but objective of this study is not to investigate short time variations. So assumption can be made of a $4 \mathrm{~m} \mathrm{~s}^{-1}$ (annual mean wind speed) wind which is set constant in speed and direction throughout simulated period. It means wind is set constant along the simulated day and the nine precedent days, so that wind change in time would not interfere with results. Wind speed and direction will be changed during the study but will never change in the current of one test.

\section{Simulations}

The first simulation is set with a normal south wind of $4 \mathrm{~m} \mathrm{~s}^{-1}$. Results of this simulation are then used as reference for the next ones. Two parameters are studied. First set of simulations is performed to observe effects of wind incidence on air movements. A second set is performed to observe density area influence. Values represented are those calculated at 12 o'clock. These are medium values in a very regular day profile, as shown in Fig. 7. With no wind, day profile follows inside-outside thermal difference variations. In this case it is far more fluctuating. Finally, a third set of simulations is pursued to illustrate simultaneous influence of incidence and environment density.

\subsection{Reference case: results}

Following parameters were introduced in M. Grosso's model: open environment, $f a r=3.7$, far $=0.8$ and normal incidence. $\mathrm{Cp}$ distributions obtained have already been presented (Fig. 3).

Results of TAS simulation done with these coefficients are shown in Fig. 8. Results are given in air change by hour
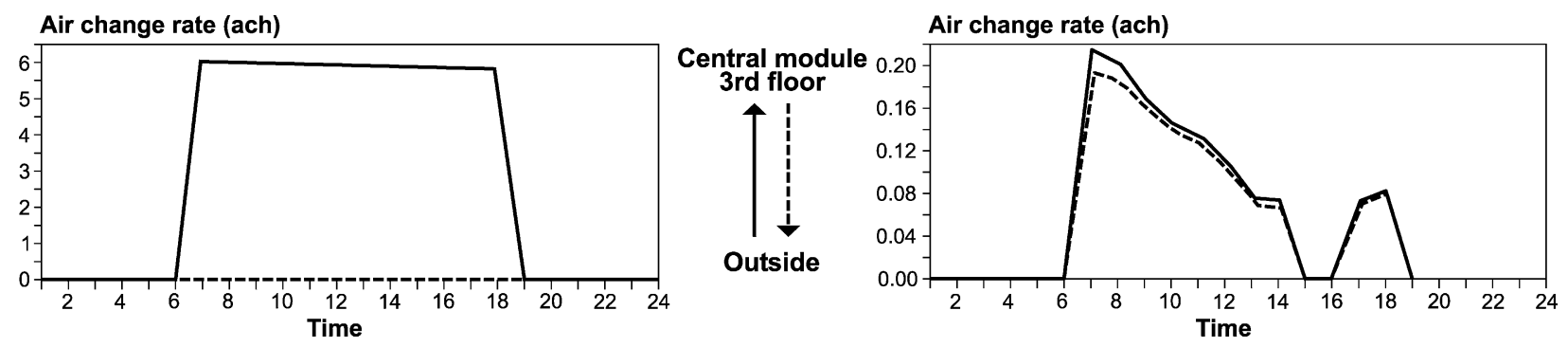

Fig. 7. Ach profile in third floor central office module for a $4 \mathrm{~m} \mathrm{~s}^{-1}$ or $0 \mathrm{~m} \mathrm{~s}^{-1}$ normal wind.

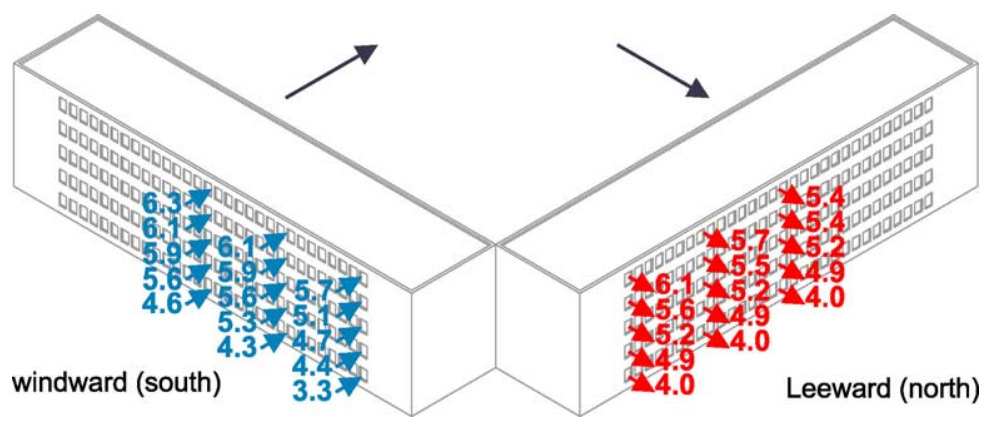

Fig. 8. ach results for a $4 \mathrm{~m} \mathrm{~s}^{-1}$ normal wind in an open environment: whole building. 


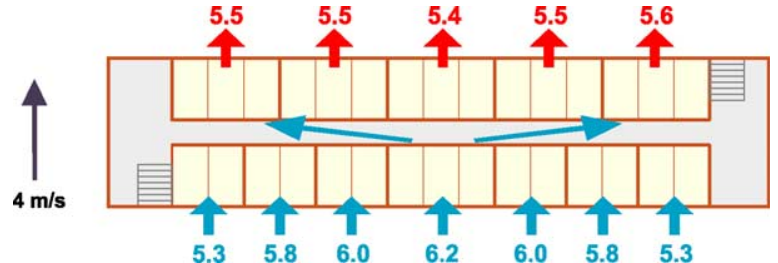

Fig. 9. ach results for a $4 \mathrm{~m} \mathrm{~s}^{-1}$ normal wind in an open environment: fourth storey, basic opening regime.

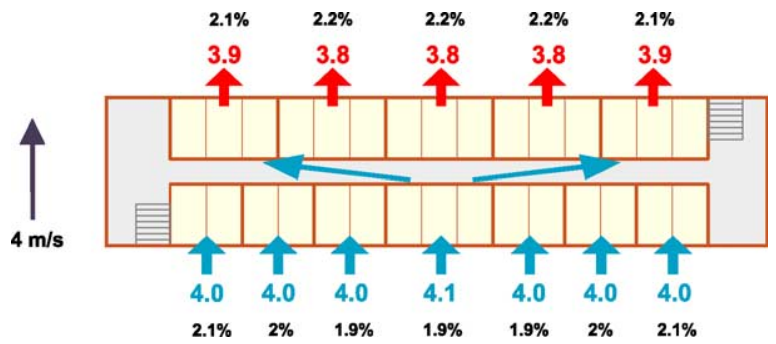

Fig. 10. ach results for a $4 \mathrm{~m} \mathrm{~s}^{-1}$ normal wind in an open environment: fourth storey, modified opening regime.

(ach) because this is the most useful unit for architects. It allows them to quickly evaluate air quality as he knows 1 ach is enough to ensure sanitary air change and more than 4 ach in typical office spaces may cause discomfort (flying papers, etc.). Windows opening regime is the following: inside wall superior opening is set $80 \%$ open, external wall superior openings are set $3 \%$ open and exterior wall inferior windows are closed. This opening regime is further called "basic opening regime".

Simulation is also made with the second zone pattern to zoom on the fourth floor. Results are shown in Fig. 9. It allows to see more accurately inside flows. This simulation was made twice: first time opening regime is the one used for the all building simulation (basic opening regime). Second time opening regime is different for each office module's outside wall superior opening. Variations were iterated to obtain a regular flow in all offices. Needed opening percentages are noted on Fig. 10.

Finally influence of leeward $\mathrm{Cp}$ distribution is investigated by introducing -0.3 leeward pressure coefficient value for all windows. Obtained results are shown in Fig. 11.

\subsection{Reference case: discussion}

Values obtained for ach with a normal incident $4 \mathrm{~m} \mathrm{~s}^{-1}$ wind in open country are between 3.3 and 6.3 (Fig. 8). This is enough to ensure air quality and an efficient refreshing effect. Obtained air change levels on windward side follow quite well pressure coefficients distribution. Of course, results are symmetrical and ach is greater in upper storeys. This tendency is true even for the last floor were windward pressure coefficients are not maximal. This is caused by an important depression on leeward side, induced by flow taking off at roof edge.

Location of most ventilated office modules is different for each side. The windward middle office module is a local maximum for each storey while leeward air change levels are far more regular, except near upper corners were a maximum appear.

Fourth storey zoom shows inside air flow between office modules which is not a simply south-north cross air flow (Fig. 9). It also shows how precise window's opening regulation must be to ensure regular air flows in different office modules (Fig. 10). The 4 ach value has been taken as objective since it allows building refreshing without discomfort for occupants.

Use of uniformed leeward pressure coefficients values modifies ach levels on both sides (Fig. 11). Ach vertical distributions are quite uniform on leeward side and far more regular on windward side, compared with reference results. Horizontal variations disappear on leeward side, also around buildings corners, while remaining on windward side. Maximal values are decreased and minimal increased. So, the way leeward pressure coefficient values are calculated is important because strongly influence results for the whole building. Choice was made here to use M. Grosso's model but as shown before results for leeward side have to be considered carefully. After all, more investigations are needed in this field. It is not sure which values to consider in order to obtain reality closest results.

\subsection{First set: results}

Figs. 12-14 show pressure distributions and consecutive TAS results obtained using identical parameters as preced-

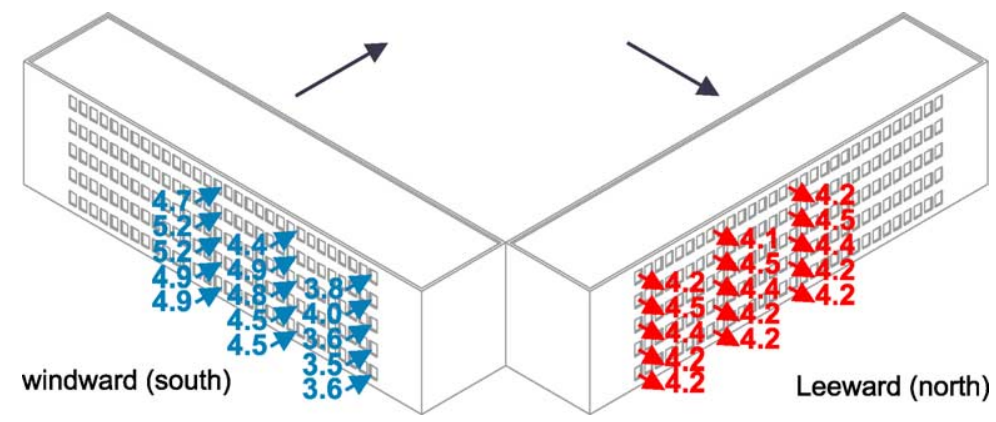

Fig. 11. ach results for a $4 \mathrm{~m} \mathrm{~s}^{-1}$ normal wind in an open environment: whole building, uniformed leeward $\mathrm{Cp}$. 


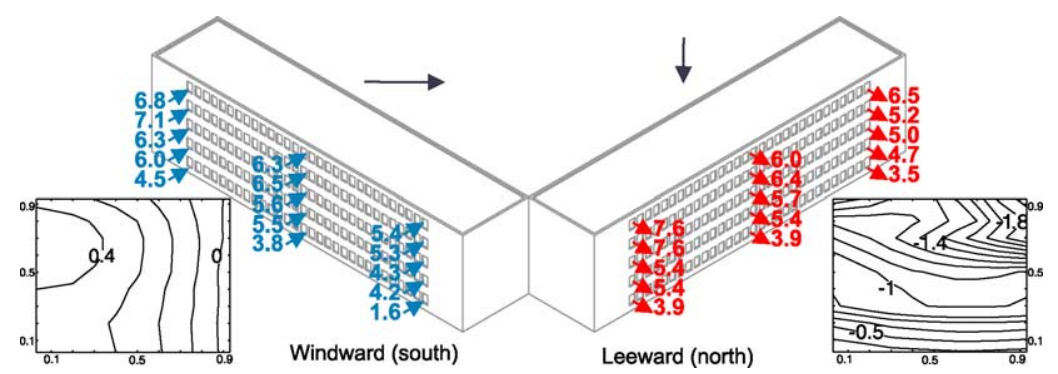

Fig. 12. Pressure coefficients obtained with M. Grosso's model (left and right) and ach results (center) for a $4 \mathrm{~m} \mathrm{~s}^{-1} 45^{\circ}$ incident wind in an open environment.

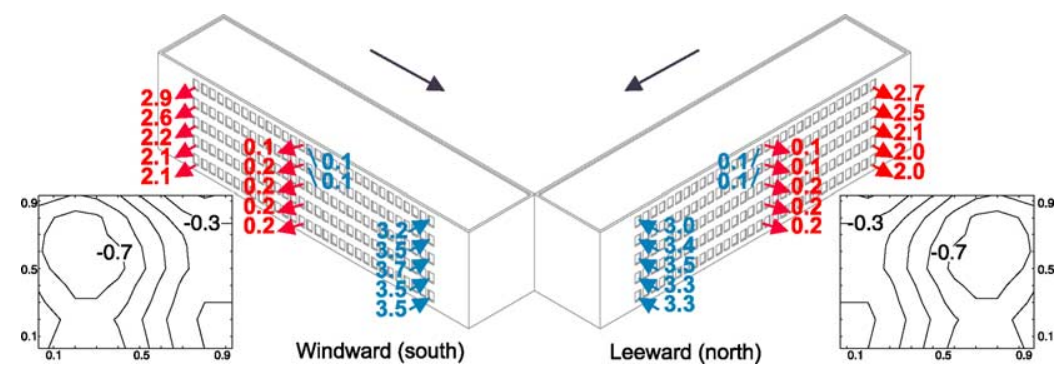

Fig. 13. Pressure coefficients obtained with M. Grosso's model (left and right) and ach results (centre) for a $4 \mathrm{~m} \mathrm{~s}^{-1} 90^{\circ}$ incident wind in an open environment.

ing simulations, except for wind incidence which is set to $45^{\circ}$ and then $90^{\circ}$. Simulations are pursued with the basic opening regime, except fourth storey simulation for a $90^{\circ}$ incidence.

\subsection{First set: discussion}

Variation in air incidence causes air movement modifications.

An incidence of $45^{\circ}$, for example, will cause inside air movement from the most upwind office modules to the most downwind modules (Fig. 12). It seems logical since major air movements occur between areas of maximal pressure gradient. This tendency exists for each storey. Two others phenomena occur: a local ach maximum on north-west fifth storey module caused by a local important depression and a minimum ach in south east first storey caused by weak pressure on windward side and weak depression on leeward side. All these observations are impossible when using mean pressure coefficients values on building sides or when limiting pressure coefficients distributions to vertical gradients.

For a $90^{\circ}$ west incidence, our results strongly differ from Gratia et al.'s. They were talking about one side ventilation. Our results show a more complex pattern with air flow moving through the whole building from downwind low depression modules to upwind strong depression modules (Fig. 13). This flow occurs on each side, leaving weak ventilated office modules on the central part of the building. These central modules are those corresponding to Gratia et al. results. Local stack effect must be managed in such modules to achieve sufficient air change level, as shown in
Fig. 14, were 4 ach were seek in each module. A $17 \%$ opening is needed as well for superior as for inferior windows on outside wall in central modules.

Such phenomenon may have influence on architectural design. As air flow divide buildings in well and poorer ventilated areas, architects may consequently choose place for rooms with different air needs (offices, files rooms, technical services, ...). It could also be an element in design of rooms with different air flow motor: two storey rooms where effective stack effect may develop, for example, could find place in such locations.

\subsection{Second set: results}

Now incidence is set back to $0^{\circ}$ (normal to south façade) and M. Grosso's parameters are taken to represent suburban or urban environments, as explained above. Figs. 15 and 16 show pressure coefficients distributions and simulated ach for the two environments.

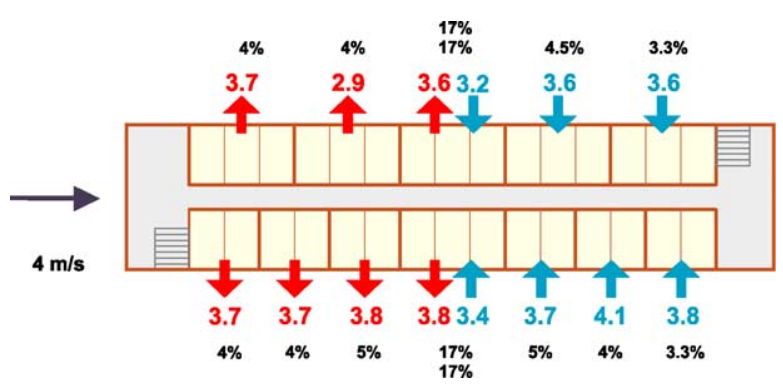

Fig. 14. ach results for a $4 \mathrm{~m} \mathrm{~s}^{-1} 90^{\circ}$ incident wind in an open environment: fourth storey, modified opening regime. 


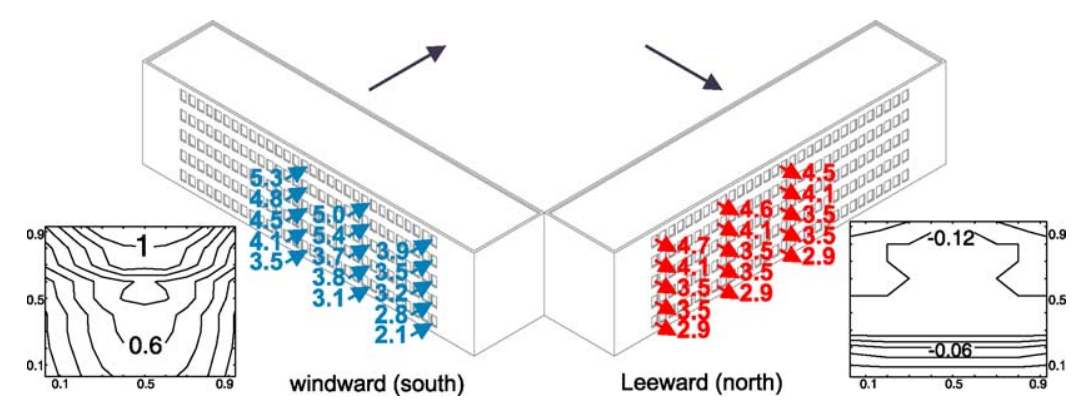

Fig. 15. Pressure coefficients obtained with M. Grosso's model (left and right) and ach results (centre) for a $4 \mathrm{~m} \mathrm{~s}^{-1}$ normal incident wind in a suburban environment.

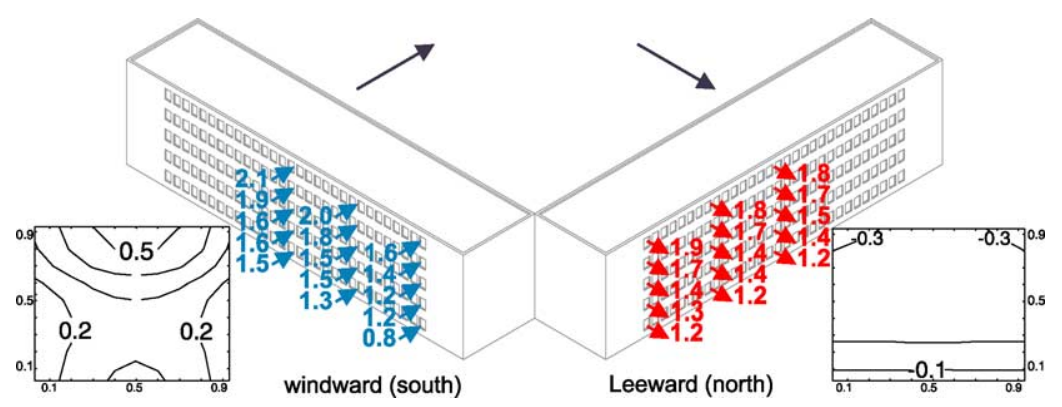

Fig. 16. Pressure coefficients obtained with M. Grosso's model (left and right) and ach results (centre) for a $4 \mathrm{~m} \mathrm{~s}^{-1}$ normal incident wind in an urban environment.

\subsection{Second set: discussion}

Two kinds of influences may be suspected for density. The first is to make a cross ventilation impossible. The second is to reduce air change rates when cross ventilation occurs. To investigate the first influence Fig. 17 shows relative day ach variation for different wind speed. Fig. 7 showed that it is a good indicator of whether cross or one side ventilation, since air speed is set constant along day. Therefore, it is a good indicator of major wind or stack effect. Considering $10 \%$ variation as a limit, cross ventilation appears below $0.7 \mathrm{~m} \mathrm{~s}^{-1}$ in open environment and $2 \mathrm{~m} \mathrm{~s}^{-1}$ in urban environment. These values are lower than mean Belgian wind measured speeds $\left(4 \mathrm{~m} \mathrm{~s}^{-1}\right.$ in open country, convertible to $2 \mathrm{~m} \mathrm{~s}^{-1}$ in urban environment. So, urban context seems compatible with wind driven ventilation. It is an important conclusion to promote natural

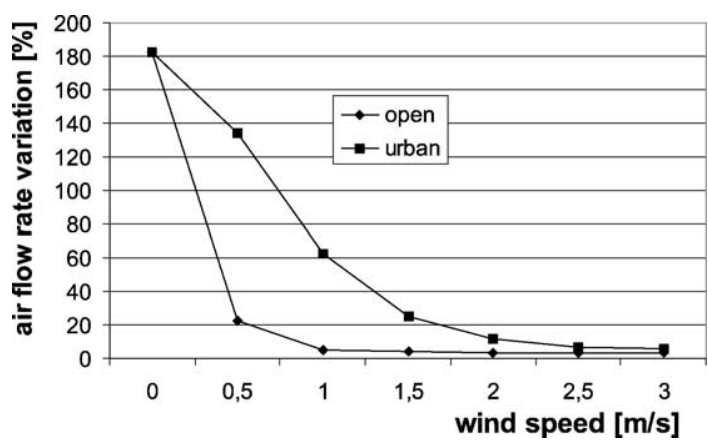

Fig. 17. Relative day ach variation following wind speed for open and urban environment. ventilation in urban area. But specific air tunnel studies stay necessary for particular cases answers.

Second influence is shown by Figs. 15 and 16 for suburban and urban environments with a $4 \mathrm{~m} \mathrm{~s}^{-1}$ normal wind. Major phenomena discussed for reference results are conserved, except ach levels which undergo global reduction (around 70\% reduction for urban environment). Once again our results do not match Gratia et al.'s, which announce one side stack driven ventilation and not cross wind driven ventilation. Origin of this difference may be found in the way urban environment is modelled. For their study, Gratia et al. considered city as an environment dense enough to see skimming flow appear. Therefore, negative pressure coefficients were considered on windward side, equal to leeward ones. Following, no cross ventilation could appear. M. Grosso's parametrical model simulates wake interference flow when used with urban description explained above. Pressure coefficients values on windward side are then positive on windward side and negative on leeward side. Cross ventilation is, therefore, a logical result.

Which study reflects reality of wind flow? There in no single answer to this question. Urban fact is a complex and variable phenomenon. Typical street of Brussels are too narrow to allow wake interference flow if following Hussain's limitations. Does it mean no cross ventilation may be developed in city? Not strictly because such limits are valid only for canyon streets with normal incidence. Other streets and places configurations are not represented. Furthermore, this study shows effective ventilation may occur for $45^{\circ}$ or $90^{\circ}$ incidences. Conclusion is that European complexity of urban forms and wind driven potentials 


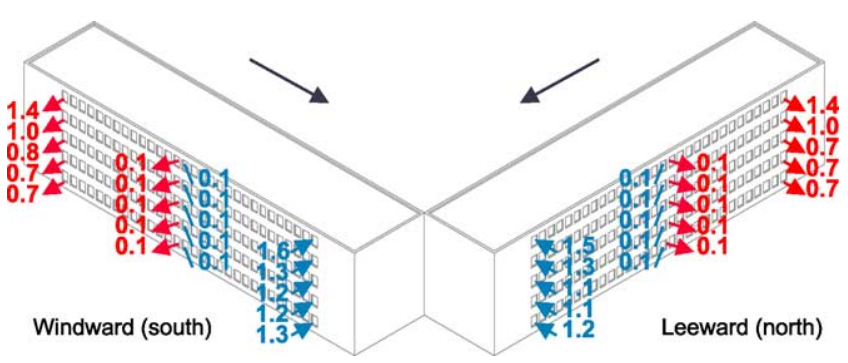

Fig. 18. ach results for a $4 \mathrm{~m} \mathrm{~s}^{-1} 90^{\circ}$ incident wind in an urban environment: whole building.

cannot be represented only by this criterion. Complete description of urban flow does not exist at the time and specific studies are still the only way to answer specific questions.

It must be recalled here that procedure used to obtain "urban" pressure coefficients is an abstraction.

\subsection{Third set: results}

The last set of simulations was followed to study influence of both incidence and density. Fig. 18 shows results for an urban environment and $90^{\circ}$ wind incidence (wind normal to lateral side).

\subsection{Third set: discussion}

For a $90^{\circ}$ incident urban wind, air movements are similar to those described in open situation but ach levels are lower (Fig. 18). Other simulations were carried out to compare effects of both incidence and density (Fig. 19). Two different influences may be distinguished. Wind incidence modifications will change inside and outside air movements but would not significantly change absolute values range of ach, as long as air flow goes through building from one side to the other. It means that results are similar for $0^{\circ}$ and $45^{\circ}$ wind incidence while $90^{\circ}$ incidence provides lower ach levels for the same opening size. This difference is especially present in open environments. On the other side, changes in environment density reduce ach levels but do not disturb significantly air movements as shown in Figs. 15 and 16.

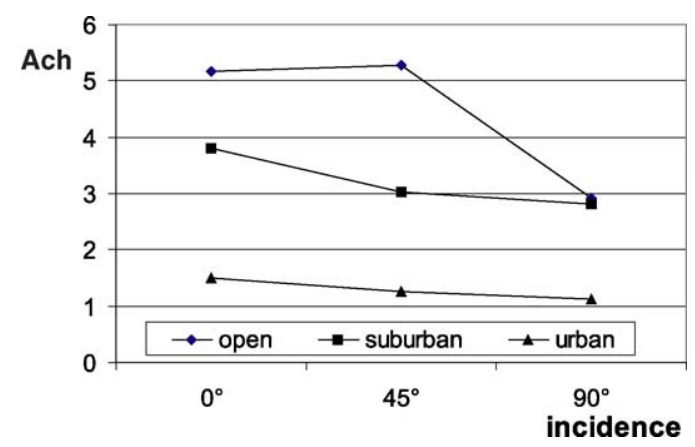

Fig. 19. Mean ach values on windward side for different environment (for $90^{\circ}$ incidence, calculation was made without central offices).

\section{Conclusion}

This study intended to bound knowledge of wind pressures on buildings with natural ventilation potential. It was done by putting in light which changes in air flow occur inside buildings when horizontal as well as vertical pressure coefficients gradients on buildings sides are considered. Investigations were carried out along with the study of two parameters: wind incidence and environment density, classified in three configurations: open, suburban and urban.

A parametrical model was used to obtain pressure coefficients distributions on buildings sides. Limitations of this model were investigated by confrontation with published wind tunnel experimental results. It was then calibrated on basis of IEA mean pressure coefficients values given for different incidences and three situations: open, semi-sheltered and sheltered. These situations were supposed equivalent to open, suburban and urban environment. Wind exponent profile values for each environment were also chosen following published studies.

Simulations were then pursued with TAS program. Results were ach levels in office modules. Initial intuition of linking between pressure coefficient distribution and complexity of inside air flow has been verified. It is demonstrated that horizontal pressure gradients calculation is necessary in natural ventilation study. Using them, obtained results are far from those of equivalent studies working only with vertical gradients. As a summary it may be said that wind incidence influences air movements qualitatively while environment density influences ach's levels.

Limitations of urban modelling have been discussed on the base of tools limited precision and only full scale measurements, wind tunnel experiments and numerical simulations could answer particular questions. Nevertheless existing tools are sufficient to pursue studies such as this one, provided that the reader keeps in mind it has an high abstraction level.

Using these tools, it is shown that Belgian mean wind regime is adequate to wind driven natural ventilation, even in urban area. More accurate studies may then be undertaken to concretely study and realise naturally ventilated buildings.

Finally, accurate windows opening regulation has been proved necessary to ensure regular ach levels throughout a building. Only mechanical regulation appears adequate because fundamental flow rates equilibrium principles connect each office modules to others.

\section{Further works}

As discussed above, results may change significantly following the way urban geometry is represented. Parametrical models limitations make them useless tools to describe accurately real urban environments. Wind tunnel and CFD investigations are most powerful tools. But this last 
needs huge time and computational resources for calculation. Nevertheless, important wind tunnel investigation campaigns may lead to more accurate parametrical models describing pressure distributions in typical urban situations as street canyon, urban place, planted streets or other typical north European streets profiles. These tools are desirable because natural ventilation represents an important potential for energy economy in northern Europe, most cooling systems for examples being running while outside temperatures are lower than inside.

In medium term new tools could be developed practical and powerful enough to work on an integrated design of a building in its environment. This is in order to ensure maximal comfort and energy performance in buildings and urban context.

Determination of precise regulation rules also seems necessary because the iterative procedure used here to obtain regular flow rates in office modules is incompatible with real fluctuating wind. Simultaneously, since hypothesis was made of time constant wind, new studies should work on time dependent ventilation. One of the study fields it opens is stack and wind forces combination to ensure constant effective ventilation.

All these studies should be carried on with global architectural comprehension. Connection of structural, environmental and aesthetic concerns is the best way to tend to a sustainable architecture.

\section{References}

[1] P.J. Richards, R.P. Hoxey, L.J. Short, Wind pressures on a $6 \mathrm{~m}$ cube, Journal of Wind Engineering and Industrial Aerodynamics 89 (2001) 1553-1564.
[2] B.G. Wiren, Effects of surrounding buildings on wind pressure distributions and ventilative heat losses for a single family house, Journal of Wind Engineering and Industrial Aerodynamics 15 (1983) 1526.

[3] Y. Jia, B.L. Sill, Pressures on a cube embedded in a uniform roughness field of variable spacing density, Journal of Wind Engineering and Industrial Aerodynamics 77-78 (1998) 491-501.

[4] M. Hussain, B.E. Lee, A wind tunnel study of mean pressure forces acting on large group of low-rise buildings, Journal of Wind Engineering and Industrial Aerodynamics 31 (1988) 41-66.

[5] J.J. Kim, J.J. Baik, H.Y. Chun, Two-dimensional numerical modelling of flow and dispersion in the presence of hill and buildings, Journal of Wind Engineering and industrial Aerodynamics 89 (2001) 947966.

[6] C.H. Chang, R.N. Meroney, Concentration and flow distribution in urban street canyons: wind-tunnel and computational data, Journal of Wind Engineering and industrial Aerodynamics 91 (2003) 11411154.

[7] A.C. Khanduri, T. Stathopoulos, C. Bédard, Wind-induced interferences effects on buildings-a review of the state-of-the-art, Engineering structures 20 (70) (1998) 617-630.

[8] R. Jozwiak, J. Kacprzyk, J.A. Zuranski, Wind-tunnel investigation of interference effects on pressure distribution on a building, Journal of Wind Engineering and industrial Aerodynamics 57 (1995) 159-166.

[9] E. Gratia, I. Bruyère, A. De Herde, How to use natural ventilation to cool narrow office buildings, Building and Environment 39 (4) (2004) $1157-1170$.

[10] J.P. Triplet, G. Roche, Météorologie générale, Météo, France, 1986.

[11] M.G. Melaragno, Wind in Architectural and Environmental Design, Van Norstrand Reinhold Company, New York, 1992.

[12] M. Grosso, Wind pressure distribution around buildings: a parametrical model, Energy and Buildings 18 (1992) 101-131.

[13] J.E. Cermak, Nature of air flow around buildings, Colorado State University Fluid Dynamics and Diffusion Laboratory Report CER7576 JEC5, Colorado State University, Fort Collins, Colorado, 1975.

[14] M.W. Liddament, Air Infiltration Calculation Techniques-An Applications Guide, International Energy Agency, 1986.

[15] A.M. Jones, EDSL Ltd., TAS, Software Package for the Thermal Analysis of Buildings, 13/14 Cofferidge Close, Stony Stratford, Milton Keynes, Mk11 1BY, United Kingdom. 